\title{
The Carbon-Based Evolutionary Theory (CBET)
}

\section{Ji-Ming Chen*}

School of Life Sciences and Engineering, Foshan University, Foshan, Guangdong Province, 528225, China

\section{${ }^{*}$ Corresponding author.}

Email: jmchen678@qq.com; Telephone: +86-13854212160.

\begin{abstract}
It is desirable to upgrade previous evolutionary theories, which have remained incomplete and controversial for decades. Here we employ the concept of carbon-based entities (CBEs), which include methane, amino acids, proteins, organisms, and other entities containing relatively many carbon atoms. We deduce the driving force, mechanisms, steps, modes, tempos of CBE evolution, through integration of biology, physics, and chemistry using logics for complex issues. We hence establish the Carbon-Based Evolutionary Theory (CBET). The CBET suggests that evolution is the increase in hierarchy, diversity, fitness of CBEs under natural selection and driven by thermodynamics due to the chemical effect of the thermodynamic features of the Earth on CBEs. It provides better explanations for life origin, macroevolution events, natural selection, sympatric speciation, and evolution tempos than previous evolutionary theories. It reveals the evolutionary basis of multiple important social notions, including diversity, collaboration, altruism, obeying rules, and proper increase in freedom. It refutes some wrong notions in thermodynamics, including negative entropy (negentropy) and that biological order is equal to thermodynamic order, which have misled many people. The CBET is supported by its deduction and application. It could be a rare bridge linking laws of thermodynamics, evolution of life, and development of human society, and could have great significance in various sciences.
\end{abstract}

\section{Keywords}

carbon-based entity; driving force; energy; entropy; evolution; fitness; mechanism; natural selection; thermodynamics; theory 


\section{Introduction}

Many evolutionary theories have been proposed. The mainstream theories are Darwin's theory emerged in the $19^{\text {th }}$ century and the Modern Synthesis emerged in the $20^{\text {th }}$ century [1-3]. Darwin's theory elucidated the importance of natural selection, and the Modern Synthesis established the genetic basis of natural selection. The definition of natural selection in Darwin's theory, survival of the fittest, is literally confusing because many individuals who are not the fittest can survive and replicate [1-3]. The Modern Synthesis reinterpreted natural selection as gradual changes in gene frequencies of populations because those individuals carrying adaptive mutations are more reproductively successful [1-3].

Darwin's theory, the Modern Synthesis, and some other evolutionary theories were extrapolated from biological observations [1-17]. This logic is prone to generate incomplete and controversial views, like the fact that different fishes have different views of the same river where they live, and no fishes could see the panorama of the river. Consequently, these theories cannot interpret life origin and some events of macroevolution (i.e. evolution above the species level), including unicellular organisms evolved to multicellular organisms, and ectotherm animals evolved to warm-blooded animals [1-5,10,18,19]. Moreover, these theories cannot integrate with multiple challenges identified in recent decades: evolution of many species showed the punctuated equilibrium tempo with little change in long geological periods and significant changes in short geological periods; many genetical mutations are neutral or even harmful in natural selection; some mutations occur not randomly; some acquired epigenetic changes are heritable and important for adaption of organisms [1-15].

Evolution is a process of thermodynamics, but evolution has not been well explained with laws of thermodynamics [1-3,20,21] (see Section 5). Moreover, evolution shows a progressive process, but previous evolutionary theories generated some prejudiced notions harmful for development of human society (see Section 5).

Together, it is desirable to upgrade previous evolutionary theories with a more scientific and comprehensive one, which can integrate with advances in biology, laws of thermodynamics, and notions useful for development of human society. To achieve this goal, we deduce from multi-disciplinary integration the Carbon-Based Evolutionary Theory (CBET) with the concept of carbon-based entities (CBEs). CBEs include methane, amino acids, proteins, nucleic acids, lipids, organisms, and other entities chemically containing relatively many carbon atoms. CBEs have hierarchies, and large organic molecules are higher-hierarchy CBEs (HHCBEs) compared 
with middle organic molecules, but they are lower-hierarchy CBEs (LHCBEs) compared with organisms.

The CBET could achieve the above goal because it employs the following five factors, which are all important for evolution and neglected by previous theories: the leading actor throughout life origin and evolution (CBEs), chemical reactions of CBEs, the temperate climate and much water on the Earth, integration of biology, physics, and chemistry, and logics for complex issues $[2,3]$.

The infant version of the CBET was published in 2000-2001 as an article and a book using mathematical methods targeting the evolution of the universe without the concept of CBE $[1,2]$. Afterward, we spent around 20 years applying it to the evolution of the surface of the Earth and making it easily understandable.

\section{The framework of the CBET (F-CBET)}

\subsection{Deduction of the driving force of evolution}

The Earth's surface has widespread temperate heat streams flowing from the Sun, geotherm, and other energy sources. The Earth, as a rare habitable planet in astronomy, receives temperate sunlight for billions of years [14]. Meanwhile, many sites on the Earth, particularly at hydrothermal vents, have emitted geothermal energy for long periods [16,17]. The Earth has much water and the atmosphere to make these heat streams more temperate, more widespread, last longer through winds, rains, and evaporation.

Widespread temperate heat streams on the Earth trigger many reactions, as per the second law of thermodynamics (heat can spontaneously flow from a hotter body to a colder body, and cannot spontaneously flow from a colder body to a hotter body. See Supplementary File) $[20,21]$. Therefore, stones can spontaneously absorb heat as much as possible from these heat streams and increase their temperatures via physical reactions; CBEs can spontaneously absorb heat as much as possible from these heat streams to form HHCBEs via chemical reactions, partially because carbon atoms are prone to form covalent and other chemical bonds after absorbing heat [22]. Numerous CBEs brought to the Earth by meteorites could also absorb heat to form HHCBEs [3,7].

Although all HHCBEs shall degrade later, some HHCBEs are relatively stable. Hence HHCBEs can be accumulated, and accumulated HHCBEs can continue to absorb heat to form further higher-hierarchy CBEs. These reactions, which have occurred at a myriad of places for billions of years on the Earth, leads to increase in hierarchy of CBEs including life origin and 
life origin (Figure 1). Therefore, the tendency of CBEs to absorb heat as much as possible from the widespread temperate heat streams on the Earth to form HHCBEs is the driving force of evolution, which can be expressed with the following formula.

CBEs $\underset{\text { release heat }}{\stackrel{\text { absorb heat }}{\rightleftarrows}}$ Higher-hierarchy CBEs $\underset{\text { release heat }}{\stackrel{\text { absorb heat }}{\rightleftarrows}}$ Further higher-hierarchy CBEs

The macroevolution events that some unicellular organisms evolved into multicellular organisms and some animal individuals (e.g. ants) evolved into eusocial societies, are consistent with the above driving force, as these events are increase in hierarchy of HHCBEs driven by thermodynamics. The macroevolution event that some ectotherm animals evolved to warmblooded animals is also consistent with the above driving force, as warm-blooded animals can absorb more heat than ectotherm animals.

Temperate heat streams and water are important for hierarch-wise CBE evolution. If heat streams were too cold, CBEs were difficult to absorb enough heat to form HHCBs. If heat streams were too hot, the formed HHCBEs could be destroyed rapidly. Besides making heat streams on the Earth more temperate, last longer, and more widely distributed, water participates in formation of HHCBEs as an important substrate and the reaction environment. Water flows facilitate CBEs to meet each other to form CBEs. Moreover, water maintains the normal structures and functions of HHCBEs.

Initially, the driving force of evolution was from sunlight and geotherm. Later, with the increase of organisms on the Earth, biological energy became a source of the driving force of evolution. This is important for animals which actively absorb heat and obtain CBEs from other organisms. Energy from coals, petrol, water flows, and atomic nucleus has been utilized by humans for development of human society.

During the whole history of the Earth, the amount and the diversity of HHCBEs including organisms on the Earth are generally increasing [23]. However, meteorite impacts, huge volcano eruptions, long glacial periods, and other catastrophes can destroy the temperate heat streams on the Earth and structures of many organisms [24-26]. Consequently, the amount and the diversity of organisms could decline greatly for these catastrophes, sometimes leading to mass extinctions [24-26].

\subsection{Deduction of the major steps of evolution}

The driving force of evolution from thermodynamics leads to hierarchy-wise formation and accumulation of HHCBEs. For example, amino acids, nucleotides and other middle organic 
molecules could not bypass the intermediate hierarchy of large organic molecules to form unicellular organisms, and large organic molecules could not bypass the intermediate hierarchy of unicellular hierarchy to form multicellular organisms. Accordingly, as per the backstepping logic (i.e. if hierarchy A exists, the hierarchies lower than hierarchy A should have existed in advance), there should be the following seven major steps of evolution on the Earth (Figure 1).

Step 7, many animal individuals of the same species collaborate with each other and form animal societies, which include societies of bees, ants, humans, and some other animals. Animal societies have novel functions which cannot be fulfilled by animal individuals. For example, some ant societies plant fungi for food [27]. Some animal societies are eusocial societies, where some individuals reduce their own lifetime reproductive potential to raise the offspring of others. Human societies are also based on individual collaboration, but they are different from animal societies in various respects. Many animals are presocial as they do not form solid societies, but families where parents take care of their own progenies [28]. Although presocial species are more common than eusocial species, eusocial species usually have large populations [28]. This is consistent with the advantages of animal societies in protecting themselves, avoiding intraspecies competition, and obtaining heat and CBEs for reproduction.

Step 6, many cells interact with each other and form multicellular organisms, which include fungi, plants, and animals.

Step 5, many complexes of large organic molecule aggregates interact with each other and form the first batch of unicellular organisms, which are CBEs having the complicated functions of self-reproduction via catalysis (for efficiently generating HHCBEs) and self-protection (for efficiently maintaining HHCBEs).

Step 4, many large organic molecule aggregates interact with each other and form complexes of large organic molecule aggregates, which, like organelles in the unicellular organisms, have some complicated functions (e.g. synthesis of proteins).

Step 3, many large organic molecules interact with each other and form large organic molecule aggregates (e.g. lipid bilayer membranes and channels allowing ions to pass lipid bilayer membranes) [29].

Step 2, many middle organic molecules (e.g. amino acids, nucleotides, glucose) interact with each other and form proteins, nucleic acids, polysaccharides, and other large organic molecules.

Step 1, many small molecules (e.g. $\mathrm{CO}_{2}, \mathrm{CH}_{4}, \mathrm{H}_{2} \mathrm{O}, \mathrm{H}_{2} \mathrm{~S}, \mathrm{NH}_{3}$ ) interact with each other and form middle organic molecules (e.g. amino acids, nucleotides, glucose). This step also occurred on other planets, and lots of CBEs were sent to the Earth by meteorites [30]. 


\section{Major views of the CBET}

Widespread relatively temperate heat streams and much water on the Earth

Trigger many physical and chemical reactions

Some carbon-based entities (CBEs) spontaneously absorb heat as much as possible to form higherhierarchy CBEs (HHCBEs) via chemical reactions Some formed HHCBEs are relatively stable, so they can be accumulated and continue to absorb heat to form further higher-hierarchy CBEs

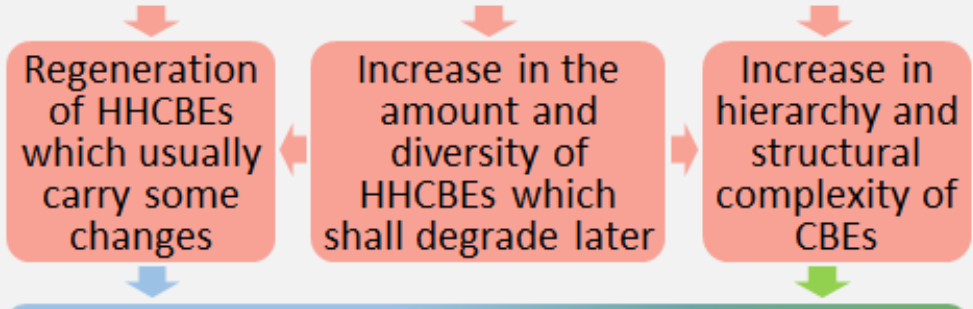

Influence on the interaction inside HHCBEs which determines the fitness and functions of HHCBES Survival of all HHCBEs fit for the environment

Increase in the fitness and functions of HHCBEs
Small inorganic and organic molecules (e.g. $\mathrm{CO}_{2}, \mathrm{CH}_{4}, \mathrm{H}_{2} \mathrm{O}, \mathrm{NH}_{3}$ )

$$
\checkmark
$$

Middle organic molecules (e.g. amino acids, nucleotides)

Large organic molecules (e.g. proteins, nucleic acids, lipids) ए.

Large organic molecule aggregates (e.g. lipid bilayer membrane) V

Complexes of large organic molecule aggregates (e.g. ribosomes)

Unicellular organisms with selfreplication \& self-protection

Multicellular organisms (e.g. fungi, plants, animals)

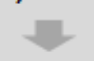

Animal societies (e.g. ant societies, bee societies, human society)

\section{Major views of \\ previous \\ mainstream theories}

Reproduction of organisms with random genetic changes

Survival of the fittest due to excessive reproduction and fierce competition

(Darwin's theory)

Gradual changes in gene frequencies as the individuals carrying adaptive mutations are more reproductively successful

(The Modern Synthesis)

\section{Speciation and}

increase in fitness of organisms

\begin{tabular}{c|c}
$\begin{array}{c}\text { These theories } \\
\text { cannot explain } \\
\text { increase of } \\
\text { these }\end{array}$ & $\begin{array}{c}\text { These theories } \\
\text { have not } \\
\text { integrated } \\
\text { with multiple } \\
\text { hierarchies }\end{array}$ \\
\begin{tabular}{c} 
challenges \\
\hline
\end{tabular}
\end{tabular}

Figure 1. Major views of the CBET versus previous mainstream evolutionary theories. Red arrows show the driving force mechanism, green arrows the structure-function mechanism, and blue arrows the natural selection mechanism. 
Steps 1-5 constitute chemical evolution which is also termed abiogenesis or life origin. Regarding life origin, previous evolutionary theories emphasize the special role of RNA (e.g. the world of RNA hypothesis) and some organic molecules with the function of autocatalysis [31], while the CBET highlights collaborative interaction, i.e. collaboration, of many organic molecules and other CBEs, which is supported by a few bacteria created by humans [32].

\subsection{Deduction of three mechanisms of evolution}

The first is termed the driving force mechanism, where the driving force of evolution directly leads to increase in the amount of HHCBEs, which is equal to increase in hierarchy and structural complexity of CBEs. Because few mechanisms exist for generation of identical HHCBEs, increase in the amount of HHCBEs means increase in diversity of HHCBEs. Therefore, the driving force mechanism leads to increase in the amount and diversity of HHCBEs, which is equal to increase in hierarchy, structural complexity, and diversity of CBEs.

The second mechanism, termed the structure-function mechanism, represents that CBEs with increased hierarchy and structural complexity spontaneously obtain some complicated functions, due to interaction inside HHCBEs. For example, although no amino acids emit fluorescence, when green fluorescence protein is formed by amino acids, it obtains spontaneously the function of emitting green fluorescence, due to interaction of amino acids.

The third mechanism, termed natural selection, represents the natural phenomenon that an HHCBE shall increase or decrease its numbers over time as per its overall fitness, and fitter HHCBEs shall increase their numbers relatively more rapidly.

The structure-function mechanism leads to numerous complicated functions under natural selection, including self-reproduction, sexual reproduction, non-random mutation, predation of animals, infection of pathogens, immunity of hosts, animal feelings, and human accumulation of knowledge [2,3]. These functions add fitness to the relevant HHCBEs. For example, nonrandom mutations as evidenced in many microbial genomes and mammalian immunoglobulin genes $[9,15]$, can be fulfilled through complicated structures of organisms, and they are useful to generate advantageous mutations and avoid disadvantageous mutations. Sexual reproduction can be fulfilled through complicated structures of organisms and generate numerous mutants, which are useful to fit different environments, through recombination of genomic sequences. This mutation strategy is less risky than nucleotide substitution, because the recombined genomic sequences have passed long-term natural selection [2,3].

Natural selection is a tautology, namely that those fit survive and those surviving are fit, and those having greater numbers are the fitter, and the fitter have greater numbers. Previously 
natural selection was criticized due to this tautology [33]. We think this tautology cannot refute natural selection, like the fact that the champion is the one who ran the fastest, and the one who ran the fastest is the champion, and a champion must be available if there is a race. Similarly, natural selection must exist naturally, because no mechanism makes all HHCBEs are formed and maintained at the equal rates. Therefore, the driving force of evolution, which leads to longterm repeated formation of HHCBEs, is the prerequisite of natural selection. Accordingly, the first leading role of evolution is not natural selection, but the driving force of evolution from thermodynamics.

Natural selection, mutation, genetic drift, or competition was claimed to be the driving force of evolution [3-5,21,34-36]. These actions are not based on energy, and they are largely mechanisms or processes of evolution, so they are not the driving force of evolution. The role of energy in biological evolution was highlighted previously [37,38], but energy has not been linked to the driving force of evolution.

\subsection{Expression of the F-CBET}

The driving force mechanism, the three mechanisms, and the major steps of evolution, as shown in Figure 1, constitute the F-CBET. Because the driving force mechanism and the structure-function mechanism are directly from the driving force of evolution, the F-CBET can be so expressed: evolution is the increase in hierarchy, diversity, and fitness of CBEs under natural selection and driven by thermodynamics due to the chemical effect of the thermodynamic features of the Earth on CBEs.

\subsection{Some social notions from the F-CBET}

Collaboration and altruism (altruism is a special type of collaboration supporting the production and functions of other entities) are important throughout CBE evolution. For example, many small molecules spontaneously collaborate each other and "sacrifice" themselves to form large organic molecules, and many molecules inside cells spontaneously collaborate each other and "sacrifice" themselves to support the replication and functions of nucleic acids, and many immune cells in multicellular organisms spontaneously collaborate each other and "sacrifice" themselves to support the production and functions of other cells. Many individuals in animal societies spontaneously collaborate each other and "sacrifice" themselves to support the existence of other individuals.

Obeying rules and restricting freedom constitute collaboration and altruism inside HHCBEs throughout CBE evolution. For example, many molecules obey rules and restrict their 
freedom in cells, and many cells obey rules and restrict their freedom in multicellular organisms. Many individuals obey rules and restrict their freedom in animal societies, including that worker bees work diligently for their societies, and human drivers obey traffic rules.

The restricted freedom should increase properly along with the increase in CBE hierarchies. Many atoms can move a little in large molecules. Many molecules can move inside cells. Many cells can move in multicellular organisms. Many animal individuals can move in certain areas.

\subsection{Reliability of the F-CBET}

The F-CBET is reliable because it is not built on novel laws, novel observations or novel experiments, but deduced mainly from classical laws of thermodynamics with some facts that are well known to be important for evolution. The growth of all known organisms is a process that CBEs absorb heat from temperate heat streams to form HHCBEs. The production of numerous organic molecules, various viruses, and some bacteria in factories or laboratories through chemical synthesis or genetic engineering [39-41], is also a process that CBEs absorb heat from temperate heat streams to form HHCBEs in a hierarchy-wise way. Moreover, all known biological reactions comply with classical laws of thermodynamics, so biological evolution complies with classical laws of thermodynamics. These facts all support the CBET.

The F-CBET provides better explanations for life origin, macroevolution events, nonrandom mutations, and altruism. These better explanations support the F-CBET.

We used about 20 minutes to explain the F-CBET to 26 undergraduate students, and they all understand and accept the F-CBET. This supports the F-CBET.

\section{Different explanations of natural selection in the CBET}

Natural selection in the CBET is different from natural selection in Darwin's theory and the Modern Synthesis in the following respects, although they all represent the sane natural process or mechanism leading to increase of fitness.

First, natural selection in the CBET applies to nonliving HHCBEs and organisms, while natural selection in previous theories is largely restricted to organisms.

Second, natural selection was expressed as "survival of the fittest” in Darwin's theory, and "gradual replacement of populations with those carrying advantageous mutations (which we summarize as "survival of the fitter")" in the Modern Synthesis [1-3], while natural selection is expressed as "survival of the fit" in the CBET, as per its tautology (those fit survive and those surviving are fit). Whether an HHCBE is fit is determined by the HHCBE and its environment 
(e.g. an HHCBE having great fitness in a forest can be unfit in a desert). "Survival of the fit" includes elimination of the fitter HHCBEs if they are not fit in harsh environments [24-26], survival of the HHCBEs less fit if they are fit in suitable environments, and that those fitter HHCBEs shall have relatively more numbers over time, which leads to increase in fitness. Therefore, those HHCBEs carrying changes advantageous, neutral or even harmful in fitness, such as those leading to life origin, multicellular organisms, warm-blooded animals, and thalassemia, can survive and replicate, if their overall fitness is adequate in suitable environments. This facilitates increase in biological diversity, and further explains some macroevolution events (e.g. it is possible that goats evolved from fish not because goats have greater fitness than fish, but because goats and fishes both have adequate fitness) [33]. This is also consistent with research advances which suggest that many genomic changes are neutral without increase in fitness, and many organisms carry disadvantageous traits and harmful mutations [3-5,10,12,34].

Third, natural selection in previous theories usually emphasizes fitness in a single aspect, while natural selection in the CBET highlights the overall fitness. For example, antelopes are less strong than buffaloes to fight against carnivores, but they run fast and have other advantages, making their overall fitness is adequate. This suggests a novel mechanism of sympatric speciation: organisms with different combinations of traits can speciate in the same ecological niche of the same area because they all have adequate overall fitness. Previously, only the mechanism for sympatric speciation targeting different ecological niches of the same area has been proposed, as different ecological niches exert different selection pressures, which render organisms evolving towards different directions [3].

Fourth, the targets of natural selection in previous theories were claimed to be individuals, populations, or genes [35,42], while all genomic sites, all traits, and all hierarchies are claimed to be under natural selection in the CBET. This is because natural selection "selects" organisms as per their overall fitness, which is influenced by all genomic sites, all traits, and all hierarchies. Therefore, natural selection functions extensively in evolution. Moreover, a conserved trait or genomic site without change during a long geological period does not mean that the trait or site is not under natural selection, but likely under strong negative selection [42].

Fifth, as per previous theories, a biological trait is usually assumed to be advantageous in natural selection, while in the CBET, a biological trait (e.g. long necks of giraffes) may be neutral, advantageous, or disadvantageous in natural selection in general. Moreover, a biological trait may be advantageous in some aspects and disadvantageous in some other aspects (e.g. long necks of giraffes are useful for finding predators, but harmful to bones and 
hearts), so this trait is under both positive selection (namely that natural selection promotes those changes which add fitness) and negative selection (namely that natural selection inhibits those changes which reduce fitness). As detailed in Supplementary File, co-action of positive selection and negative selection on the same trait provides a comprehensive explanation for the widespread evolutionary tempo of punctuated equilibrium.

Sixth, previous definitions of natural selection targeted only inheritable changes, while in the CBET, genetic mutations, epigenetic changes, and uninheritable changes all influence the overall fitness of HHCBEs, and they are thus all under natural selection. For example, vaccination makes many animals survive viral infections and pass the relevant natural selection.

Together, the above details of the CBET provide better explanations for prevalent neutral or disadvantageous mutations, effects of uninheritable traits on fitness, sympatric speciation, and punctuated equilibrium. These better explanations support these details of the CBET.

\section{Complex logics employed and demonstrated in the CBET}

As sparsely mentioned in above sections with comprehensible examples and generalized in Supplementary File, the CBET employs and demonstrates some Complex logics (e.g. the one showing that tautology can be correct, and the one constitutes the structure-function mechanism) [2].

\section{Significance of the CBET}

For biology, the CBET is more scientific and comprehensive than previous theories, because the CBET is deduced from laws of thermodynamics, and as given in Sections 2.6 and 3, it provides better explanations for multiple evolutionary issues than previous evolutionary theories. The CBET reveals the prerequisite of natural selection.

For social sciences, the CBET reveals the evolutionary basis of various notions important for harmonious development of human society. Previous evolutionary theories highlight selfishness, competition, and elimination of those less fit in certain traits [1-5,24]. These prejudiced notions have been employed to justify authoritarianism, racism, fascism, and Nazism [43]. The CBET not only emphasizes selfishness, fitness, and competition in natural selection, but also emphasizes diversity, collaboration, altruism, obeying rules, and proper increase in freedom. The above notions of the CBET are all important for harmonious development of human society.

For physics, the CBET reveals for the first time the driving force and mechanisms of evolution through integration with multiple disciplines including thermodynamics, in a comprehensible way. Previously, physicists neglected the five factors which are all important 
for evolution and listed in Section 1, and they did not employ the simple expression of the second law of thermodynamics to explain evolution, and they did not reveal the driving force or mechanism in a direct and comprehensible way [44-50]. Although some notions or theories in thermodynamics, such as negative entropy (negentropy) and the dissipative structure theory, have been employed to explain evolution [44-50], as detailed in Supplementary File, these notions or theories are elusive, controversial, or even wrong, mainly because scientists were misled by the wrong notion that biological order is equal to thermodynamic order [44-50]. Biological order is accumulated slowly through long-term natural selection and requires movements of microscopic particles, while thermodynamic order can increase rapidly by releasing heat to the surroundings and requires microscopic particles to be static (e.g. cold perfect crystals have low entropy and high thermodynamic order). When a seal is dying in ice and becoming cold, its entropy is declining with increase in its thermodynamic order and decrease in its biological order. Biological order supports high entropy of an organism because biological order supports relatively rapid movement of microscopic particles in the organism, like the fact that traffic order supports relatively rapid running of cars in a metropolis. Therefore, the notion that biological order is equal to thermodynamic order is wrong, and the notion of negentropy is wrong because negentropy was built on the wrong notion that biological order is equal to thermodynamic order.

\section{Conclusions}

This article deduces a novel evolutionary theory termed the CBET, which is quite different from previous theories (Figure 1 and Table 1), through integration of biology, physics, chemistry using logics for complex issues. The CBET suggests that evolution is the increase in hierarchy, diversity, and fitness of CBEs driven by thermodynamics due to the chemical effect of the thermodynamic features of the Earth on CBEs, and the increase is under natural selection whose explanations are different from previous theories in several respects.

The CBET is more scientific and comprehensive than previous evolutionary theories. It provides the prerequisite for natural selection and better explanations for multiple evolutionary issues. It reveals the evolutionary basis of multiple important social notions. It refutes some wrong thermodynamic notions regarding evolution which have misled many people. The CBET is reliable as per its deduction and application. This theory could be a rare bridge linking laws of thermodynamics, evolution of life, and development of human society. It could hence have great significance in natural sciences and social sciences. 
Table 1. Differences between previous mainstream evolutionary theories and the CBET.

\begin{tabular}{|c|c|c|}
\hline Aspects & Previous mainstream theories & The CBET \\
\hline Logic & $\begin{array}{l}\text { These theories employ logics } \\
\text { for simple issues to determine } \\
\text { their details and frameworks } \\
\text { via extrapolation from } \\
\text { biological observations }\end{array}$ & $\begin{array}{l}\text { The CBET employs logics for complex } \\
\text { issues to determine its details using } \\
\text { biological observations, and determines } \\
\text { its framework via deduction through } \\
\text { multi-disciplinary integration }\end{array}$ \\
\hline $\begin{array}{l}\text { The driving } \\
\text { force of } \\
\text { evolution }\end{array}$ & $\begin{array}{l}\text { Natural selection, genetic drift, } \\
\text { mutation, or competition (none } \\
\text { of them directly involve } \\
\text { energy) }\end{array}$ & $\begin{array}{l}\text { Carbon-based entities (CBEs) absorb heat } \\
\text { as much as possible from heat streams on } \\
\text { the Earth to form higher-hierarchy CBEs } \\
\text { (HHCBEs) }\end{array}$ \\
\hline $\begin{array}{l}\text { Progressive } \\
\text { mechanisms } \\
\text { of evolution }\end{array}$ & $\begin{array}{l}\text { Natural selection, sexual } \\
\text { selection, and epigenetic } \\
\text { changes lead to increase in } \\
\text { fitness of organisms; } \\
\text { mechanisms of life origin and } \\
\text { macroevolution remain } \\
\text { unknown }\end{array}$ & $\begin{array}{l}\text { The driving force increases the structural } \\
\text { complexity and hierarchy of CBEs; CBEs } \\
\text { with increased structural complexity and } \\
\text { hierarchy obtain spontaneously some } \\
\text { complicated functions; natural selection } \\
\text { leads to increase in diversity and fitness } \\
\text { of HHCBEs }\end{array}$ \\
\hline $\begin{array}{l}\text { Natural } \\
\text { selection }\end{array}$ & $\begin{array}{l}\text { Defined as "survival of the } \\
\text { fittest" or gradual replacement } \\
\text { of populations with those } \\
\text { carrying advantageous } \\
\text { mutations; highlighting } \\
\text { advantageous mutations; } \\
\text { highlighting selection in a } \\
\text { single aspect; claiming that } \\
\text { mutations occur randomly and } \\
\text { only inheritable changes are } \\
\text { under natural selection }\end{array}$ & $\begin{array}{l}\text { "Survival of the fit" which includes } \\
\text { survival of those less fit and elimination } \\
\text { of the fitter as per the environmental } \\
\text { changes; highlighting neutral mutations } \\
\text { and diversity; allowing disadvantageous } \\
\text { traits; highlighting the overall fitness } \\
\text { constituted by all traits; highlighting } \\
\text { selection in various aspects; accepting } \\
\text { non-random mutations and that } \\
\text { inheritable changes and uninheritable } \\
\text { changes are all under natural selection }\end{array}$ \\
\hline $\begin{array}{l}\text { Chemical } \\
\text { evolution or } \\
\text { life origin }\end{array}$ & $\begin{array}{l}\text { Neither the driving force nor } \\
\text { the mechanisms have been } \\
\text { proposed to interpret how } \\
\text { large organic molecules } \\
\text { evolved into lives; RNA and } \\
\text { autocatalysis are highlighted }\end{array}$ & $\begin{array}{l}\text { The driving force and mechanisms of } \\
\text { chemical evolution are revealed; lives } \\
\text { originated hierarchy-wise from small } \\
\text { molecules with several intermediate } \\
\text { hierarchies; collaboration of various } \\
\text { molecules is highlighted }\end{array}$ \\
\hline $\begin{array}{l}\text { Sympatric } \\
\text { speciation }\end{array}$ & $\begin{array}{l}\text { No mechanism was proposed } \\
\text { for sympatric speciation in the } \\
\text { same niche of the same area }\end{array}$ & $\begin{array}{l}\text { Different combinations of various traits } \\
\text { can all constitute adequate fitness in the } \\
\text { same niche of the same area }\end{array}$ \\
\hline $\begin{array}{l}\text { Animal } \\
\text { societies }\end{array}$ & $\begin{array}{l}\text { Neglecting the hierarchy of } \\
\text { animal societies in evolution; } \\
\text { difficult to explain some social } \\
\text { notions; having negative } \\
\text { influence on development of } \\
\text { human society }\end{array}$ & $\begin{array}{l}\text { Listing the hierarchy of animal societies } \\
\text { in evolution; revealing the evolutionary } \\
\text { basis of important social notions } \\
\text { including competition, collaboration, } \\
\text { altruism, obeying rules, increase in } \\
\text { freedom }\end{array}$ \\
\hline $\begin{array}{l}\text { General } \\
\text { features }\end{array}$ & $\begin{array}{l}\text { Incomplete, unable to integrate } \\
\text { with multiple challenges, } \\
\text { unable to integrate with } \\
\text { physics and social sciences }\end{array}$ & $\begin{array}{l}\text { Comprehensive, able to integrate with } \\
\text { multiple challenges, able to integrate with } \\
\text { laws of thermodynamics and } \\
\text { development of human society }\end{array}$ \\
\hline
\end{tabular}


Acknowledgements: This study has not been supported by any funds. The author thanks Jiwang Chen, Meng Yang, Yiqing Chen, and many other people for providing precious comments on this study.

Author contributions: This study is completed by Ji-Ming Chen.

Competing interests: The author declares no conflict of interest.

\section{References}

1. Chen JM. A new evolutionary theory deduced mathematically from entropy amplification. Chin Sci Bul. 2000;45(1):91-96. https://doi.org/10.1007/BF02884912

2. Chen JM, Chen JW. Root of science - the driving force and mechanisms of the extensive evolution. Beijing, China: Science Press, 2000.

3. Futuyma DJ, Kirkpatrick M. Evolution (4th ed). Sunderland, UK: Sinauer Press, 2017.

4. Huneman P, Walsh DM. Challenging the Modern Synthesis: adaptation, development, and inheritance. Oxford, UK: Oxford University Press, 2017.

5. Preiner M, Asche S, Becker S, et al. The future of origin of life research: bridging decades-old divisions. Life (Basel). 2020;10(3):20. http://doi.org/10.3390/life10030020

6. Pagel M. Natural selection 150 years on. Nature. 2009;457:808-811. https://doi.org/10.1038/nature07889

7. d'Ischia M, Manini P, Moracci M, et al. Astrochemistry and astrobiology: materials science in wonderland? Int J Mol Sci. 2019;20(17):4079. http://doi.org/10.3390/ijms20174079

8. Orgel L. In the beginning. Nature. 2006;439(7079):915-915. https://doi.org/10.1038/439915a

9. Fitzgerald DM, Rosenberg SM. What is mutation? A chapter in the series: How microbes “jeopardize” the modern synthesis. PLoS Genet. 2019;15(4):e1007995. https://doi.org/10.1371/journal.pgen.1007995

10. Koonin EV. Darwinian evolution in the light of genomics. Nucleic Acids Res. 2009;37(4):1011-1034. http://doi.org/10.1093/nar/gkp089

11. Dickins TE, Rahman Q. The extended evolutionary synthesis and the role of soft inheritance in evolution. Proc Biol Sci. 2012;279(1740):2913-2921. http://doi.org/10.1098/rspb.2012.0273

12. Casillas S, Barbadilla A. Molecular population genetics. Genetics. 2017;205(3):10031035. https://doi.org/10.1534/genetics.116.196493 
13. Walker SI. Origins of life: a problem for physics, a key issues review. Rep Prog Phys. 2017;80(9):092601. https://doi.org/10.1088/1361-6633/aa7804

14. Seager S. Exoplanet habitability. Science. 2013;340(577):577-581. http://doi.org/10.1126/science.1232226

15. Olivieri DN, Mirete-Bachiller S, Gambón-Deza F. Insights into the evolution of IG genes in Amphibians and Reptiles. Dev Comp Immunol. 2020:103868. https://doi.org/10.1016/j.dci.2020.103868

16. Dodd MS, Papineau D, Grenne T, et al. Evidence for early life in earth's oldest hydrothermal vent precipitates. Nature. 2017;543(7643):60-64. http://doi.org/10.1038/nature21377

17. Proskurowski G, Lilley MD, Seewald JS, et al. Abiogenic hydrocarbon production at lost city hydrothermal field. Science. 2008;319(5863):604-607. http://doi.org/10.1126/science.1151194

18. Benton MJ. The Red Queen and the Court Jester: species diversity and the role of biotic and abiotic factors through time. Science. 2009;323(5915):728-732. http://doi.org/10.1126/science.1157719

19. Lynch M. The frailty of adaptive hypotheses for the origins of organismal complexity. Proc Natl Acad Sci U S A. 2007;104(Suppl 1):8597-8604. http://doi.org/10.1073/pnas.0702207104

20. DeVoe H. Thermodynamics and chemistry (2nd Ed). http://www2.chem.umd.edu/thermobook/v10-screen.pdf. Accessed on Sep. 20, 2020.

21. Borgnakke C, Sonntag RE. Fundamentals of Thermodynamics (8th Ed). Hoboken, USA: John Wiley \& Sons, 2013.

22. Carbon. https://en.wikipedia.org/wiki/Carbon. Accessed on Sep. 20, 2020.

23. Rohde RA, Muller RA. Cycles in fossil diversity. Nature. 2005;434(7030):208-210. http://doi.org/10.1038/nature03339

24. Percival LME, Ruhl M, Hesselbo SP, et al. Mercury evidence for pulsed volcanism during the end-Triassic mass extinction. Proc Natl Acad Sci U S A. 2017;114(30):79297934. http://doi.org/10.1073/pnas.1705378114

25. Fields BD, Melott AL, Ellis J, et al. Supernova triggers for end-Devonian extinctions. Proc Natl Acad Sci U S A. 2020;117(35):21008-21010. http://doi.org/10.1073/pnas.2013774117 
26. Bader J, Jungclaus J, Krivova N, et al. Global temperature modes shed light on the Holocene temperature conundrum. Nat Commun. 2020;11:4726. https://doi.org/10.1038/s41467-020-18478-6

27. Styrsky JD, Eubanks MD. Ecological consequences of interactions between ants and honeydew-producing insects. Proc Biol Sci. 2007;274(1607):151-164. http://doi.org/10.1098/rspb.2006.3701

28. Nowak M, Tarnita C, Wilson E. The evolution of eusociality. Nature. 2010;466:10571062. https://doi.org/10.1038/nature09205

29. Levy E, Erba E, Robinson C, et al. Assembly reflects evolution of protein complexes. Nature. 2008;453:1262-1265. https://doi.org/10.1038/nature06942

30. Follmann H, Brownson C. Darwin's warm little pond revisited: From molecules to the origin of life. Naturwissenschaften. 2009;96(11):1265-1292. http://doi.org/10.1007/s00114-009-0602-1

31. Robertson MP, Joyce GF. The origins of the RNA world. Cold Spring Harb Perspect Biol. 2012;4(5):a003608. http://doi.org/10.1101/cshperspect.a003608

32. Hutchison CA 3rd, Chuang RY, Noskov VN, et al. Design and synthesis of a minimal bacterial genome. Science. 2016;351(6280):aad6253. http://doi.org/10.1126/science.aad6253..

33. Hunt T. Reconsidering the logical structure of the theory of natural selection. Commun Integr Biol. 2014;7(6):e972848. https://doi.org/10.4161/19420889.2014.972848

34. McGee MD, Borstein SR, Meier JI, et al. The ecological and genomic basis of explosive adaptive radiation. Nature. 2020. https://doi.org/10.1038/s41586-020-2652-7

35. Nei M. Mutation-driven evolution. Oxford, UK: Oxford University Press, 2013.

36. Hershberg R, Petrov DA. Selection on codon bias. Annu Rev Genet. 2008;42(1):287299. http://doi.org/10.1146/annurev.genet.42.110807.091442

37. Martin WF, Sousa FL, Lane N. Energy at life's origin. Science. 2014;344:1092-1093. https://doi.org/10.1126/science.1251653

38. Sousa FL, Thiergart T, Landan G, et al. Early bioenergetic evolution. Philos Trans R Soc Lond B Biol Sci. 2013;368(1622):20130088. http://doi.org/10.1098/rstb.2013.0088

39. Hutchison CA 3rd, Chuang RY, Noskov VN, et al. Design and synthesis of a minimal bacterial genome. Science. 2016;351(6280):aad6253. https://doi.org/10.1126/science.aad6253

40. Service RF. Synthetic biology. Synthetic microbe has fewest genes, but many mysteries. Science. 2016;351(6280):1380-1381. https://doi.org/10.1126/science.351.6280.1380 
41. Stobart CC, Moore ML. RNA virus reverse genetics and vaccine design. Viruses. 2;6(7):2531-2550. https://doi.org/10.3390/v6072531

42. Chen J, Sun Y. Variation in the analysis of positively selected sites using nonsynonymous/synonymous rate ratios: An example using influenza virus. PLoS One. 2011;6(5):e19996. http://doi.org/10.1371/journal.pone.0019996

43. Rudman LA, Saud LH. Justifying social inequalities: The role of social Darwinism. Pers Soc Psychol B. 2020;46(7):1139-1155. https://doi.org/10.1177/0146167219896924

44. Boltzmann L. The second law of thermodynamics. In Theoretical physics and philosophical problems (pp. 13-32). Dordrecht, Netherlands: Springer, 1974.

45. Schrödinger E. What is life - the physical aspect of the living cell. Cambridge, UK: Cambridge University Press, 1944.

46. Wilson JA. Entropy, not negentropy. Nature, 1968;219:535-536. https://doi.org/10.1038/219535a0

47. Kleidon A. Life, hierarchy, and the thermodynamic machinery of planet Earth. Phys Life Rev. 2010;7(4):424-460. https://doi.org/10.1016/j.plrev.2010.10.002

48. Ramstead MJD, Badcock PB, Friston KJ. Answering Schrödinger's question: A freeenergy formulation. Phys Life Rev. 2018;24:1-16. https://doi.org/10.1016/j.plrev.2017.09.001

49. Jennings RC, Belgio E, Zucchelli G. Photosystem I, when excited in the chlorophyll Qy absorption band, feeds on negative entropy. Biophys Chem. 2018;233:36-46. https://doi.org/10.1016/j.bpc.2017.12.002

50. Bejan A. Evolution in thermodynamics. Appl Phys Rev. 2017;4(1):011305. https://doi.org/10.1063/1.4978611 